\title{
Putting Cities Back on Their Feet
}

\author{
Donald Shoup ${ }^{1}$
}

\begin{abstract}
Broken sidewalks have become an important legal issue since 2002 when the United States Court of Appeals for the Ninth Circuit ruled that the Americans with Disabilities Act (ADA) applies to sidewalks. As one way to comply with the ADA, cities can require property owners to repair any broken sidewalk fronting their property before they sell the property. Before any real estate is sold, the city inspects the sidewalk fronting the property. If the sidewalk is in good condition, the city does not require the owner to do anything. If the sidewalk is broken, however, the city requires the owner to repair it before selling the property. Analysis of sales data shows that if Los Angeles had adopted a point-of-sale program in 1995, about half of the city's 4,600 miles of broken sidewalks would have been repaired by 2007 . A walkable city needs walkable sidewalks. Requiring sidewalk repairs when property is sold can help put cities back on their feet.
\end{abstract}

DOI: $10.1061 /(A S C E) U P .1943-5444.0000024$

CE Database subject headings: Infrastructure; Sidewalks; Handicapped persons; Pedestrians; Urban areas.

Author keywords: Infrastructure; Sidewalks; Americans with Disabilities Act; Point-of-sale.

\section{Introduction}

Public infrastructure often decays invisibly and we are shocked when a bridge collapses or a water main breaks. Sidewalks, however, decay right before our eyes and under our feet. Sometimes we even trip over a cracked sidewalk and end up in the emergency room.

In Los Angeles, for example, 4,600 miles of the city's 10,750 miles of sidewalks need some degree of repair at an estimated cost of $\$ 1.2$ billion. Fig. 1 shows examples of these broken sidewalks. The city repaired only 67 miles of broken sidewalks per year between 2000 and 2008. Even if the sidewalks miraculously stopped breaking, at the current pace it would take 69 years to repair all the existing damage.

Broken sidewalks make the city less walkable and they especially impede people with disabilities. This impediment has become an important legal issue since the United States Court of Appeals for the Ninth Circuit ruled in 2002 in Barden v. City of Sacramento that the Americans with Disabilities Act (ADA) applies to city sidewalks. In 2003 the United States Supreme Court declined to overturn the Ninth Circuit ruling.

\section{Americans with Disabilities Act}

In Barden v. City of Sacramento, a class-action suit filed on behalf of persons with disabilities, Joan Barden and others alleged that Sacramento violated the ADA by allowing its sidewalks to fall into disrepair. The Ninth Circuit Court ruled that the ADA covers

${ }^{1}$ Dept. of Urban Planning, Univ. of California-Los Angeles, Los Angeles, CA 90095-1656.

Note. This manuscript was submitted on September 18, 2008; approved on December 2, 2009; published online on December 5, 2009. Discussion period open until February 1, 2011; separate discussions must be submitted for individual papers. This paper is part of the Journal of Urban Planning and Development, Vol. 136, No. 3, September 1, 2010. (c)ASCE, ISSN 0733-9488/2010/3-225-233/\$25.00. "anything a public entity does" and any "normal function of a governmental entity," including sidewalks (Class Action Settlement Agreement, 3).
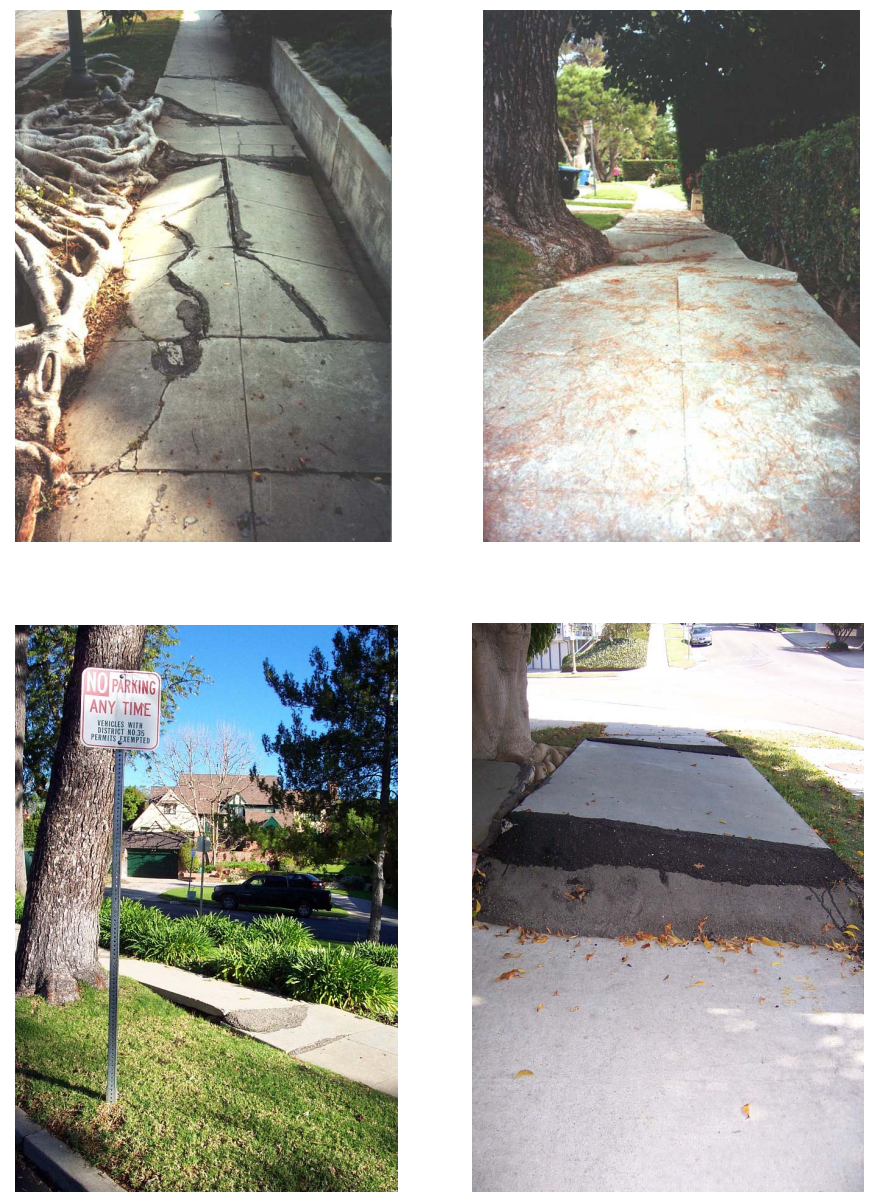

Fig. 1. Broken sidewalks in Los Angeles 
After the U.S. Supreme Court denied Sacramento's appeal, the city agreed to dedicate $20 \%$ of its annual transportation budget for up to 30 years to make public sidewalks accessible. Specifically, the settlement requires the following: "changes of level of greater than $1 / 2$ in., whether caused by tree roots or any other deterioration or displacement of the surface of the Pedestrian Right of Way, will be remedied by providing a ramp with an appropriate slope or by creating a level path of travel" (Class Action Settlement Agreement, 13).

The plaintiffs in Barden v. City of Sacramento had asked the city to adopt a transition plan to remove barriers to persons with disabilities. Section 35.150 of the regulations implementing the ADA requires all cities to have a transition plan that sets forth the steps they will take to make public facilities accessible. At a minimum, the plan shall "(1) identify physical obstacles in the public entity's facilities that limit the accessibility of its programs or activities to individuals with disabilities, (2) describe in detail the methods that will be used to make the facilities accessible, and (3) specify the schedule for taking the steps necessary to achieve compliance with this section and, if the time period of the transition plan is longer than one year, identify steps that will be taken during each year of the transition period."

Inaccessible sidewalks have also led to other ADA lawsuits. For example, Kohrman and Nepveu $(2008,5)$ discussed a classaction lawsuit against the California Department of Transportation. They reported that one plaintiff "frequently has been required to ride in the street in his wheelchair just inches alongside speeding vehicular traffic because of inadequate or absent curb cuts, ramps, or sidewalks. Because many curb cuts and slopes do not comply with the law, he is often in danger of tipping over on dangerously slanted rights of way." This complaint accurately describes the problem with many sidewalks in Los Angeles and other cities.

\section{Who Should Pay to Repair Sidewalks?}

The California Streets and Highways Code states that property owners are liable for repairing sidewalks:

"The owners of lots or portions of lots fronting on any portion of a public street shall maintain any sidewalk in such condition that the sidewalk will not endanger persons or property and maintain it in a condition which will not interfere with the public convenience.... When any portion of the sidewalk is out of repair or pending reconstruction and in condition to endanger persons or property or in condition to interfere with the public convenience in the use of such sidewalk, the superintendent of streets shall notify the owner or person in possession of the property fronting on that portion of such sidewalk so out of repair to repair the sidewalk" (Sections 5610 and 5611).

This code requires cities to notify property owners whose sidewalks are damaged. If the owner does not repair the sidewalk, the city makes the repairs and bills the owner.

Property owners in other states are also responsible for repairing sidewalks. In 2008, the Los Angeles Bureau of Street Services surveyed 82 cities in 45 states to learn who is responsible for the cost of sidewalk repairs. The survey found that property owners pay for repairs in 33 cities, the city pays in 11 cities, and the city and the property owners share the cost in 38 cities. The survey also found that inspections triggered the requirements to repair sidewalks in 44 cities, complaints in 43 cities, applications for a building permit in two cities, and sales of properties in one city. Some cities reported more than one trigger.
Los Angeles followed the state code until 1973 when federal funds became available to repair sidewalks at no cost to property owners. Because of this federal funding, the City Council adopted an exception to its previous policy of requiring property owners to pay for repairs. Section 62.104 of the Los Angeles Municipal Code, adopted in 1973, states, "Preventive measures and repairs or reconstruction to curbs, driveways, or sidewalks required as the result of tree root growth shall be repaired by the Board at no cost to the adjoining property owner." In effect, the city assumed responsibility for most sidewalk repairs.

Three years later the federal funds ran out, leaving the city with no sidewalk repair program. Then, in 1978, California voters adopted Proposition 13 to limit property tax rates and public funds became even scarcer. By 1980, when the city attempted to reinstate the previous policy of requiring property owners to pay for sidewalk repairs, the tax revolt was in full swing. Property owners objected to the "new" mandate for sidewalk repairs, so the city halted citations. Because the city was short of money, it began to make only temporary asphalt patches to cracked sidewalks or-more often-did nothing at all.

In 1998, after allowing its sidewalks to deteriorate for more than two decades, Los Angeles placed Proposition JJ on the ballot. This proposition would have authorized $\$ 769$ million in bonds to repair the sidewalks. To repay the debt, property taxes would have been increased for 20 years-even on property with no sidewalks or with sidewalks in good condition. Opponents argued that a citywide tax did not guarantee the sidewalks in front of their own homes would ever be repaired, and they had a point. Most residents would have waited years before the city fixed their sidewalks. On election day, only $43 \%$ of the voters supported Proposition JJ-far short of the two-thirds majority California requires to approve municipal bonds.

In 2000 , the city began to repair sidewalks using general revenue. The total cost to repair the accumulated damage had ballooned to $\$ 1.2$ billion, but the budget for repairs averaged only $\$ 10.8$ million per year up to 2008 . This slow pace leads to a question: Is there another way to pay for sidewalk repairs?

\section{Requiring Sidewalk Repairs at the Point of Sale}

Although Los Angeles voters have rejected a tax to repair sidewalks, the city can adopt a new strategy that already works well in other cities: require owners to repair broken sidewalks before they sell their property. How does this strategy work? Before any sale, the city inspects the sidewalk fronting the property. If the sidewalk is damaged, the owner must fix it before completing the sale. In Piedmont, California, for example, Sections 18.26-28 of the municipal code state, "New sidewalks and/or driveways must be constructed if required by the superintendent of streets... in conjunction with the sale of real property." Piedmont requires repairs if the vertical displacement of a break in the sidewalk is $3 / 4$ of $1 \mathrm{in}$. or less and reconstruction if the vertical displacement exceeds $3 / 4$ of 1 in. Pasadena, California, has a similar at-sale sidewalk repair program.

Point-of-sale programs like those in Piedmont and Pasadena have several advantages. First, the city does not require owners to pay for or do anything until they sell their property. The sale then provides the cash to pay for required repairs. Moreover, sellers fix only the sidewalk fronting their own property, so they can see exactly where their money is going.

Second, sidewalk repairs are gradual but inevitable because about half of all properties are sold at least once every decade. 
The property turnover rate is similar throughout the city, so the sidewalks are repaired everywhere at roughly the same rate (Shoup 1996). Cities will be able to renew themselves without raising taxes and without trying to do everything at once.

Third, sidewalk repairs can increase a property's "curb appeal" and thus increase its market value. A property's value will increase not only because of its own sidewalk repairs but also because of all the other repairs nearby. In return for accepting the obligation to repair one's own sidewalk before sale, everyone in the neighborhood will benefit.

Fourth, the city does not have to raise taxes to pay for sidewalk repairs. The city even saves money because of fewer tripand-fall lawsuits.

Fifth, some properties are sold by absentee owners or by residents who are leaving the city. Everyone who continues to live in the city will benefit from the sidewalk repairs paid for by these nonresidents.

Finally, the city will have a legally enforceable transition plan to make its sidewalks accessible for persons with disabilities.

\section{How Does a Point-of-Sale Program Work?}

Cities have adopted point-of-sale programs for a variety of purposes. To conserve water, for example, Los Angeles requires owners to install water-saving toilets when they sell a property. How can a city use the point-of-sale strategy to bring sidewalks up to ADA standards? In 2007, the Los Angeles Bureau of Street Services, which is responsible for the city's sidewalks, appointed a committee to study this issue. After considering all the options, the committee recommended a point-of-sale program.

To enforce a sidewalk point-of-sale mandate, the city can require that a certificate of compliance with the sidewalk ordinance must be included in the escrow documents at sale. Fig. 2 shows a flowchart of the steps necessary to obtain the certificate. The process starts when an owner requests the city to inspect a sidewalk before sale. Several outcomes are possible.

1. If the sidewalk is in good repair, the inspector issues a compliance certificate.

2. If there is no sidewalk, the inspector issues a compliance certificate.

3. If the sidewalk is damaged, the inspector estimates what the city would charge to repair it. The owner has several options at this point.

a. The owner requests the city to repair the sidewalk and pays the estimated cost. The inspector then issues a compliance certificate, and the city repairs the sidewalk.

b. The owner requests the city to repair the sidewalk and accepts a lien on the property for the estimated cost. The inspector then issues a compliance certificate, and the city repairs the sidewalk. The lien plus accrued interest is cleared at sale and the city is paid from the proceeds.

c. The owner chooses to have a private contractor carry out the work.

(1) The owner or contractor requests a permit and completes the work.

(2) The city inspects the work, and if it passes, the inspector issues a compliance certificate.

d. If the next owner intends to redevelop the property, repairing the sidewalk at sale may be premature. In this case, the city can allow the seller to contract with the

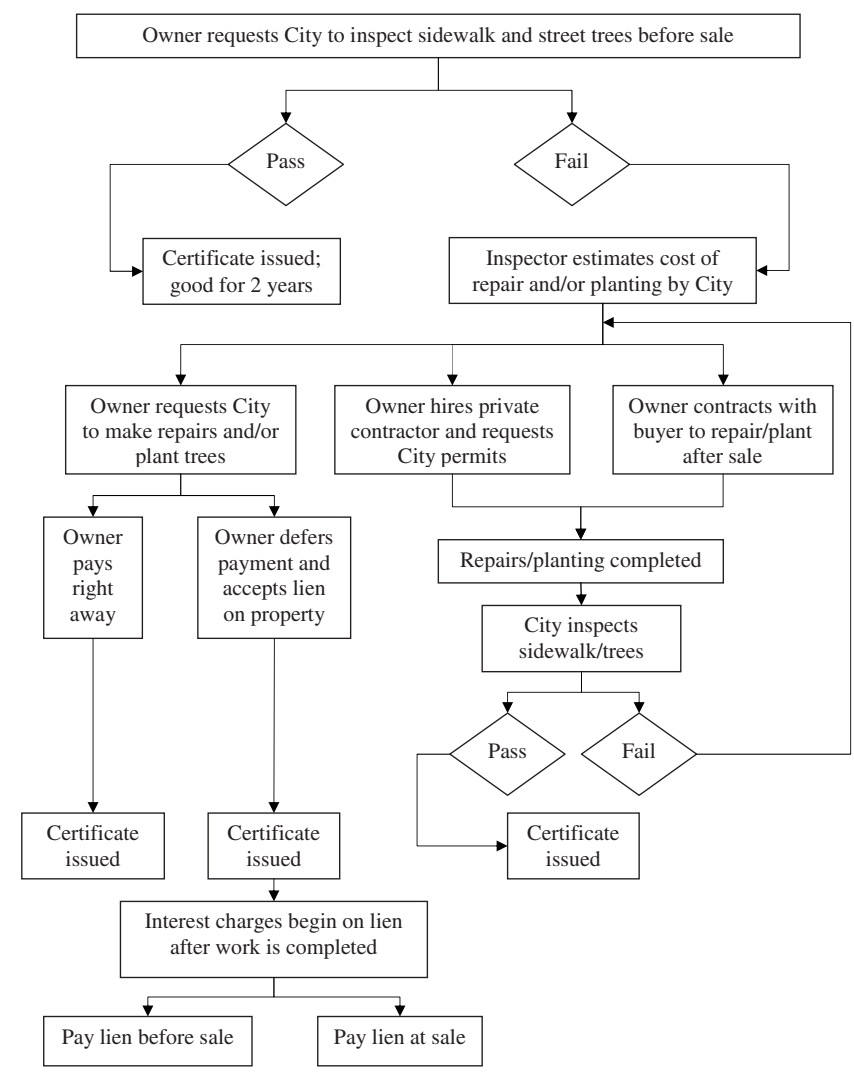

Fig. 2. Obtaining a certificate of compliance before sale

buyer to have the work done within a specified time period after sale (such as one year). The city can inspect the property at the end of this period and cite the new owner if the required repairs have not been completed.

Piedmont charges $\$ 30$ for issuing a certificate of compliance, which is the city's estimated cost of making the inspection. The inspectors can enter the records into a geographic database that shows the condition of sidewalks throughout the city. The pointof-sale program can be part of the city's transition plan to make its public sidewalks accessible, and the point-of-sale database will show the city's progress toward meeting the plan's goals.

Condominium ownership presents a problem. Would the unit owner or the condominium association be liable for repairs when a unit is sold? One solution would be to exempt individual units but require all condominium associations to repair their sidewalks within five years after the ordinance is adopted, for example, with periodic inspections to ensure continued compliance.

\section{Deferring Payments until Sale}

The basic point-of-sale plan will not require cities to advance any money to finance sidewalk repairs. If owners pay the city (either before sale or at sale) to make the repairs, the city will have idle funds to invest between the payment and the repairs. Cities can also go beyond the basic point-of-sale plan by agreeing to repair sidewalks before sale and receive payment when escrow closes. If an owner requests the city to repair a sidewalk before sale but prefers to delay payment until sale, the city can place an interestbearing lien on the property for the cost of the repairs. In this case the city is paid from the proceeds of the sale when all liens are 
cleared. The city can, in effect, lend owners the money to pay for sidewalk repairs for as long as they continue to own the property. Owners can repay all or part of the debt at any time before they sell the property, but any remaining debt is due at sale. If owners pay a market interest rate on the debt, the government loses nothing by the delay.

Some cities already allow property owners to defer paying special assessments, with interest, until they sell their property (Shoup 1980, 1990, 1994). This option to pay at sale has several benefits. First, the program increases public investment without any public subsidy. The city runs little risk of borrowers' defaulting on the cost of sidewalk repairs because cash is available from the sale of the property when the debt is due. A public lien is senior to any mortgage, so even if property values decline and the owner has no equity, the city will be repaid in full. Where land values are high and sidewalk improvements raise them further, most owners will have more than sufficient equity to repay the cost of repairs, plus accrued interest, at sale. Owners can always pay before sale to avoid the interest expense.

Second, deferring payments until sale has a strong political advantage. If the city offers to finance the cost of sidewalk repairs until cash from the sale gives owners the ability to pay, elected officials can vote for a point-of-sale requirement with a clear conscience. Offering owners the option to defer payment until sale can thus increase the political will to require sidewalk repairs. Finding the cash to repair the sidewalk before sale could be difficult for many owners, but allowing owners to pay for sidewalk repairs at sale will eliminate any cash-flow problem. Offering the option to defer payment until sale will also allow the city to cite property owners whose severely damaged sidewalks create an immediate danger to pedestrians and increase the likelihood of a trip-and-fall lawsuit (see the examples in Fig. 1). Requiring prompt repairs in these cases will increase public safety, remove barriers to persons with disabilities, and reduce claims from tripand-fall lawsuits, but it will not create a financial hardship for either property owners or the city.

Third, because an ADA transition plan aims to make sidewalks accessible as quickly as possible, cities can allow all owners to repair their sidewalks early and defer payment until sale. The requirement to repair sidewalks at sale, combined with the ability to delay payment until sale, may spur some owners to repair their sidewalks early. They may repair early because (a) they want the safe sidewalk they will eventually have to provide anyway; (b) they expect it will be cheaper to repair early; (c) they want to avoid trip-and-fall injuries; (d) they want to increase their property value; and/or (e) they want to make their property more accessible to persons with disabilities.

\section{Microloans for Public Investments}

To encourage early repairs, cities can offer to pay the cost and recoup the investment plus accrued interest when properties are sold. In effect, cities will make microloans to property owners to fund public investments. But how can the city finance an unknown quantity of future sidewalk repairs if it cannot afford a conventional repair program? One option is to borrow the money from the city's interest-earning investment pool and to repay the cost plus interest at sale. If this is not possible, the city can borrow in the municipal bond market or contract with private financial institutions to fund the repairs.

If the city contracts with a private financial institution to fund the repairs, the lenders in this public-private partnership will be repaid when liens are cleared as properties are sold. Because the property liens will pay for public investments, the interest payments will be tax exempt to the lenders. The debts will be short term, tax exempt, and almost totally default proof even if property values decline. The deferred debts for sidewalk repairs may be an attractive investment for many lenders, and the interest rate charged to the property owners should thus be low. The private lenders can administer the sidewalk debts like mortgages. The city can also notify property owners about the debt, plus accrued interest, on their annual property tax bills. In choosing among prospective lenders for the program, cities can select the one that offers property owners the lowest interest rate on the deferred payments or instead certify several lenders and let individual property owners choose the one that offers the best deal.

The collateral for most loans will be high because the cost of a sidewalk repair is low compared with the value of most property. Although the individual loans will be small, their total value can be quite high if a lender funds many of the sidewalk repairs throughout a city. Lenders might even partner with local construction companies to repair sidewalks in accordance with city regulations and the ADA. The consortium could both repair sidewalks and finance the cost until properties are sold.

Public-private partnerships have become a major source of project finance for large public infrastructure investments, such as bridges or toll roads. Financing a collection of individual sidewalk repairs will be a new form of distributed project finance in which the lender will finance a collection of many small projects rather than one big project. A collection of microloans for sidewalk repairs will have much greater collateral, much lower risk, and much shorter payback period than a conventional revenue bond for a single large infrastructure project. Financing the deferred payments for sidewalk repairs may therefore be a profitable investment for risk-averse lenders who prefer tax-free income.

\section{Speed of Repairs}

How fast will a point-of-sale program repair a city's sidewalks? For instance, how long will it take before half the broken sidewalks have been repaired? We can answer this question by estimating the time it takes before half the properties in the city have been sold at least once. Table 1 shows the history of property sales for the City of Los Angeles between 1977 and 2006.

Column 2 shows the number of properties that were sold in each year of Column 1 and were not sold again through the end of 2006, so repeated sales of the same property are not double counted. For example, 16,129 properties were sold in 1995 and had not been sold again by the end of 2006 .

Column 3 shows the total number of properties that had been sold at least once between the beginning of each year in Column 1 and the end of 2006; this total is the cumulated number of properties in Column 2. For example, Column 3 shows that 386,093 of the 769,000 properties in the city were sold at least once between the beginning of 1995 and the end of 2006.

Finally, Column 4 shows the share of properties that were sold at least once between the beginning of each year and the end of 2006. For example, $50 \%$ of properties were sold at least once between 1995 and 2006. If the sidewalks fronting the sold properties are as likely to need repair as the sidewalks fronting all properties, a point-of-sale program adopted in 1995 would have fixed $50 \%$ of all broken sidewalks in the city by the end of 2006 .

Fig. 3 shows a graph of the property sales rates. The vertical axis shows the share of properties in 2007 that were sold at least 
Table 1. Share of Properties in Los Angeles Sold at Least Once between January 1 of Each Year and December 31, 2006

\begin{tabular}{|c|c|c|c|}
\hline Year & $\begin{array}{l}\text { Number of } \\
\text { properties with } \\
\text { last sale date } \\
\text { in each year }\end{array}$ & $\begin{array}{c}\text { Total number } \\
\text { of properties } \\
\text { sold since } \\
\text { each year }\end{array}$ & $\begin{array}{c}\text { Share of all } \\
\text { properties sold } \\
\text { since each year } \\
(\%)\end{array}$ \\
\hline (1) & (2) & (3) & (4) \\
\hline 2006 & 45,327 & 45,327 & 6 \\
\hline 2005 & 47,470 & 92,797 & 12 \\
\hline 2004 & 44,921 & 137,718 & 18 \\
\hline 2003 & 43,127 & 180,845 & 24 \\
\hline 2002 & 38,155 & 219,000 & 28 \\
\hline 2001 & 30,984 & 249,984 & 33 \\
\hline 2000 & 27,412 & 277,396 & 36 \\
\hline 1999 & 27,169 & 304,565 & 40 \\
\hline 1998 & 24,982 & 329,547 & 43 \\
\hline 1997 & 21,453 & 351,000 & 46 \\
\hline 1996 & 18,964 & 369,964 & 48 \\
\hline 1995 & 16,129 & 386,093 & 50 \\
\hline 1994 & 15,679 & 401,772 & 52 \\
\hline 1993 & 13,793 & 415,565 & 54 \\
\hline 1992 & 11,930 & 427,495 & 56 \\
\hline 1991 & 11,279 & 438,774 & 57 \\
\hline 1990 & 10,970 & 449,744 & 58 \\
\hline 1989 & 12,571 & 462,315 & 60 \\
\hline 1988 & 15,359 & 477,674 & 62 \\
\hline 1987 & 16,886 & 494,560 & 64 \\
\hline 1986 & 18,873 & 513,433 & 67 \\
\hline 1985 & 13,275 & 526,708 & 68 \\
\hline 1984 & 10,259 & 536,967 & 70 \\
\hline 1983 & 8,848 & 545,815 & 71 \\
\hline 1982 & 5,967 & 551,782 & 72 \\
\hline 1981 & 6,086 & 557,868 & 73 \\
\hline 1980 & 7,118 & 564,986 & 73 \\
\hline 1979 & 10,130 & 575,116 & 75 \\
\hline 1978 & 10,369 & 585,485 & 76 \\
\hline 1977 & 10,473 & 595,958 & 78 \\
\hline
\end{tabular}

Note: Calculated by N. Wong of UCLA's Center for neighborhood knowledge. The Los Angeles County Assessor provided the last sale date for all properties in the City of Los Angeles. once during the previous number of years on the horizontal axis. The graph shows the share of the sidewalks that would have been repaired by 2007 as a function of how long ago the point-of-sale program began. If the program had begun 12 years earlier, $50 \%$ of all the broken sidewalks would have been fixed by 2007. We can call the number of years it takes for half of all properties to be sold the half-life of property ownership, and it measures how quickly sidewalks will be repaired. The shorter the half-life, the sooner sidewalks will be repaired.

In addition to the sales rate for all properties (taken from Column 4 of Table 1), the graph also shows the sales rates for several categories of properties. Commercial and industrial properties have slightly slower sales rates than residential properties, but the results are similar for all categories. Although a point-of-sale program might seem slow to produce results, city planning often produces slow results, and some planning produces no results at all. Compared to many planning efforts, a point-of-sale program can quickly improve the city.

Periodic booms and busts in real estate sales will temporarily accelerate and decelerate sidewalk repairs. Nevertheless, about half of all owner-occupied housing units in the United States are sold at least once within each decade, similar to the rate for the City of Los Angeles (Shoup 1996). Because short-term fluctuations in sales have little effect on long-term sales rates, they will have little effect on the long-term rate of sidewalk repairs.

If the city allows owners to delay paying the cost until sale, some owners may repair early. Inspectors who require repairs at sale could solicit nearby property owners whose sidewalks are cracked and suggest they too might want to participate when work is being done on their block. If owners know the repairs will have to be done eventually and the cost can be delayed until sale, some may decide to repair their sidewalks long before they sell their property. For these reasons, the actual repair rate should be faster than the sales rate in Fig. 3.

The "broken windows" theory suggests that if broken windows in a building are not repaired, vandals may break more windows. A similar "repaired sidewalks" theory would suggest that if some property sellers repair their sidewalks and all others know that they must repair their sidewalks eventually, other owners may repair their sidewalks early.

If some neighborhoods have slower-than-average sales rates,

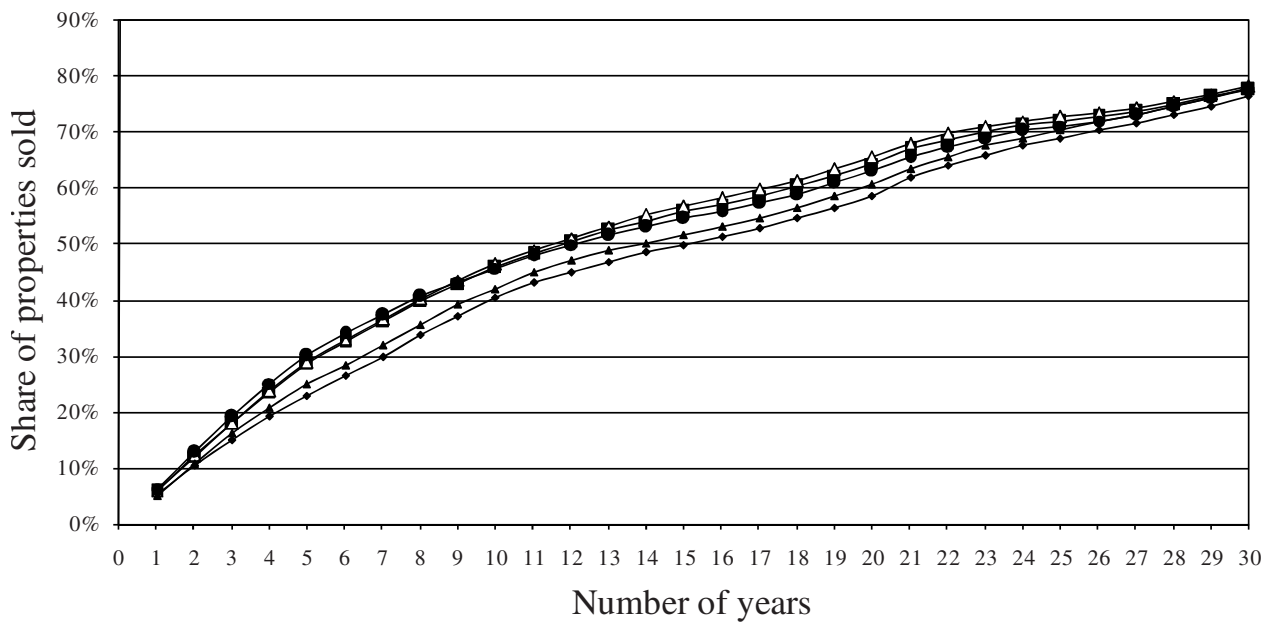

$\hookrightarrow$ All properties $\rightarrow-$ Single family $\rightarrow$ Multifamily $\rightarrow$ Commercial $\rightarrow$ Industrial

Fig. 3. Share of properties in Los Angeles sold between 1977 and 2007 
the point-of-sale policy can create geographical inequities in sidewalk repairs. Census data, however, suggest that this is not a problem. For example, the property sales rates for both the City and County of Los Angeles are almost the same as for the United States as a whole (Shoup 1996, 367). The sales rates for Beverly Hills and Compton are also almost identical. Because these two cities epitomize the differences between rich and poor communities in Southern California, their similar sales rates suggest that a neighborhood's income will not affect its rate of sidewalk repairs.

\section{Economic Effects of Requiring Sidewalk Repairs at Sale}

How will a point-of-sale program affect the economy? Investment in sidewalk repairs will increase local employment, but diverting money to pay for these repairs will reduce private consumption. Public investment, however, creates more local jobs than private consumption does because more of the goods and services used to produce public investment are local rather than imported from outside the region. To see how a point-of-sale program can affect the economy, I have used a model of the Southern California economy to estimate how the sidewalk repairs will alter local employment and income.

The Lusk Center for Real Estate at the University of Southern California has adapted the IMPLAN input-output model to represent the economy of Los Angeles, Orange, Riverside, San Bernardino, and Ventura Counties. This 509-sector model makes it possible to estimate not only the direct effects created by spending changes but also the indirect and induced effects created by intersectoral linkages. The model can thus estimate the net effects of increasing public investment and reducing private consumption.

We can use the model to estimate the effects of the point-ofsale program in the first full year of operation. The first row of Table 1 shows that $6 \%$ of all properties in the city were sold in 2006. If the point-of-sale program had begun in 2006, and if the sidewalks fronting these properties were representative of all sidewalks in the city, $6 \%$ of all broken sidewalks in the city would have been repaired in the first year of the program. The Bureau of Street Services has estimated that repairing all the broken sidewalks in Los Angeles would cost about $\$ 1.2$ billion. The total repair costs in the first year would therefore be about $\$ 72$ million $(\$ 1.2$ billion $\times 0.06)$.

Suppose owners spend $\$ 72$ million to repair their sidewalks and they pay for these repairs by spending $\$ 72$ million less on private consumption. We can estimate the effect of reducing private consumption by reducing the final demand for every consumption category in proportion to its share of consumption found in the Consumer Expenditure Survey conducted by the $\mathrm{Bu}-$ reau of Labor Statistics. Estimating the effect of increasing public investment in sidewalks is more difficult because the input-output matrix does not have a category for repairing sidewalks. The closest analogy in the matrix is maintaining and repairing streets, which is similar in its labor demands to repairing sidewalks. Therefore, the effect of increasing spending on sidewalks is estimated by increasing spending on streets. Table 2 shows the results of shifting $\$ 72$ million from private consumption to repairing sidewalks.

Shifting $\$ 72$ million a year from private consumption to public investment will eliminate 1,656 existing jobs and create 1,750 new jobs. The shift will therefore produce a net increase of 94 local jobs. The eliminated jobs pay an average wage of $\$ 30,900$ a year, while the created jobs pay an average wage of $\$ 35,600$ a year. The shift from private consumption to public investment not only creates more jobs than it eliminates, but the created jobs also pay $\$ 4,700$ a year more than the eliminated jobs.

Reducing private consumption by $\$ 72$ million a year will reduce local wages by $\$ 51$ million, while spending $\$ 72$ million on sidewalk repairs will increase local wages by $\$ 62$ million. The shift from private consumption to public investment will therefore increase total local wages by $\$ 11$ million ( $\$ 62$ million - \$51 million). Proprietary income (the income received by selfemployed individuals, such as contractors) also increases by $\$ 6$ million a year. As a result of these changes, in its first year a point-of-sale sidewalk repair program will increase total labor income in Southern California by $\$ 17$ million ( $\$ 11$ million $+\$ 6$ million).

Why does spending for sidewalks increase local wages more than spending for private consumption does? Many of the goods and services consumed by Southern Californians are not produced in the region (such as cars from Germany, clothes from China, gasoline from Venezuela, whisky from Scotland, and wine from Napa). In contrast, sidewalks are repaired locally (we cannot import them). Therefore, shifting spending from private consumption to repairing sidewalks will increase the demand for local labor.

The sidewalk repairs are assumed to be financed by reducing local private consumption. Absentee owners and residents who leave the region after sale will reduce their consumption elsewhere. The point-of-sale program can therefore stimulate economic activity within Southern California even more than estimated here.

These rough estimates suggest that a point-of-sale program will increase local employment and income, but that is not the reason to repair sidewalks. The point-of-sale program will save money in settling trip-and-fall lawsuits, increase property values, be politically feasible, help the city comply with the ADA, and allow the city to do something that almost everybody wantsrepair broken sidewalks. At the very least, the model results show

Table 2. Effects of Shifting $\$ 72$ Million from Private Consumption to Public Investment

\begin{tabular}{llcrr}
\hline & Private consumption & Public investment & Net change \\
\hline 1 & Spending & $-\$ 72,000,000$ & $+\$ 72,000,000$ & $+1,750$ \\
2 & Jobs & $-1,656$ & $\$ 30$ \\
3 & Average wage per job & $\$ 30,900$ & +94 \\
4 & Total wages & $-\$ 51,264,000$ & $+\$ 62,208,000$ & $+\$ 1,700$ \\
5 & Proprietary income & $-\$ 9,000,000$ & $+\$ 14,904,000$ & $+\$ 5,904,000$ \\
6 & Total labor income & $-\$ 60,264,000$ & $+\$ 77,112,000$ & $+\$ 16,848,000$ \\
\hline
\end{tabular}

Note: Calculated by Q. Pan using the 2001 IMPLAN model for Southern California. The region consists of Los Angeles, Orange, Riverside, San Bernardino, and Ventura Counties. 
that the point-of-sale program will not hurt the economy.

For job-creation programs, politics are often more important than economics. If spending for private consumption declines slightly, the resulting job losses will be invisible in an economy that creates and destroys tens of thousands of jobs a month. In contrast, most of the 1,750 jobs created by public spending are easily seen. In Los Angeles, the 85,000-member Service Employees International Union Local 721, which represents city employees who repair sidewalks, has strongly supported a point-of-sale program. Repairing broken sidewalks will benefit almost everyone in the city, but the jobs created by these repairs may be a stronger incentive for political leaders to act.

\section{Opposition to Requiring Sidewalk Repairs at Sale}

Despite the advantages of requiring sidewalk repairs at sale, the proposal has aroused some opposition. When the Los Angeles City Council began to consider the point-of-sale program in 2008, four associations of realtors wrote to the Council to protest it:

"We strongly protest the suggested Point of Sale mandate for sidewalk repair.... The Point-of-Sale program as proposed simply will not meet the City's goal to fix the $\$ 1$ billion backlog of broken sidewalks and reduce the average $\$ 3$ million in liability settlements paid out every year due to trip-and-fall injuries" (Memo to the Los Angeles City Council, p. 1, 2008).

The realtors instead proposed issuing bonds to finance sidewalk repairs: "No serious discussion has yet occurred to explore this option. Repairs funded by bond moneys [sic] will get the job done at no additional cost to the city." The realtors seemed unaware that cities must increase taxes to repay bonds and that, in 1998, Los Angeles voters had rejected a proposition to issue $\$ 769$ million in bonds to repair sidewalks.

Realtors also oppose other point-of-sale programs. For example, Los Angeles requires the installation of gas shut-off valves when properties are sold. These motion-sensitive valves shut off the gas supply to a building after an earthquake. The city adopted this requirement after many gas pipes broke in the Northridge earthquake in 1994, and the escaping gas fueled catastrophic fires. Realtors opposed gas shut-off valves at sale on the same grounds they now oppose sidewalk repairs at sale, claiming "the measure will slow home sales" (Martin 1996, 1997). Nevertheless, almost half of all properties in the city were sold at least once in 10 years after the program was adopted in 1997. If a point-of-sale program for sidewalk repairs had been adopted in 1997, about 1,060 miles of broken sidewalks $(4,600 \times 46 \%)$ would have been repaired by 2007.

Two quotes from the website of the Southland Regional Association of REALTORS help explain why they object to the pointof-sale program. (Real estate brokers often capitalize all the letters in their copyrighted name.)

"REALTORS are a special interest group working to promote and protect private property rights and to protect and promote the brokerage and management of real estate. . . We are against point of sale items because it $[$ sic $]$ increases the work load and liability of REALTORS" (Website of the Southland Regional Association of REALTORS, Inc., accessed on May 16, 2009).

Nothing could be clearer than that. In their own words, realtors are a special interest group who oppose point-of-sale programs because the requirements would increase their work load. In effect, realtors argue for the right to sell property with broken sidewalks that endanger pedestrians, impede the disabled, and increase the city's liability for trip-and-fall lawsuits. Property has its duties as well as its rights, but realtors seem to focus on the rights, not the duties.

If cities do adopt point-of-sale sidewalk programs, the realtors' initial objections may seem, in retrospect, misguided. Sidewalk repairs should increase the curb appeal of properties and thus increase both property values and the realtors' commissions on the sales. Once again we can quote the experts. According to Jim Link, chief executive officer of the Southland Regional Association of REALTORS,

"A broken sidewalk is the first sign of potentially more serious problems afflicting a neighborhood. Fixing damaged sidewalks may prevent a neighborhood from going into decline, protect property values, improve the environment, and make homeowners proud" (Website of the Southland Regional Association of REALTORS, Inc., accessed on May 16, 2009)."

Realtors thus acknowledge that broken sidewalks threaten both the public interest and property owners' private interests. If I were trying to sell a property, I would not want prospective buyers to have to pick their way along a cracked sidewalk to get to the front door. Cracked sidewalks show that a city has neglected its public infrastructure for many years. As a consequence, some prospective buyers may look for property in other cities that do maintain their sidewalks. After all, if a city will not maintain sidewalks that everyone can see, what is it doing about the other public infrastructure we cannot see?

A point-of-sale program will require me to repair any damaged sidewalk before I sell my property, but it will also require all other owners to repair any damaged sidewalks before they sell their property. Entire neighborhoods will improve. My property value (and thus the realtor's commission) will increase not only because of my own repaired sidewalk but also because of the whole neighborhood's repaired sidewalks.

Part of the value realtors offer is their ability to navigate municipal regulations, and a point-of-sale regulation can make realtors even more necessary. They can become a key source of information about the new requirement for owners who want to sell their property. Realtors' experience with obtaining the required compliance certificates can improve the services they provide for property owners. Once realtors have become familiar with the program, they may regret their previous complaints that it would increase their work load. After all, the work they do is what makes realtors useful in property transactions.

When real estate values are declining, mortgage lenders may also object to the point-of-sale program. Lenders would have to pay for any sidewalk repairs when the owner has no equity. If sidewalk repairs increase the sale prices by less than their cost, the lenders would lose money. It would be a mistake, however, to think this is a long-term problem. Any point-of-sale program would probably not start until well after the current real estate crisis fades into history. Exempting foreclosures and short sales from the point-of-sale requirement could remove a political objection to the point-of-sale program, with little effect on the longrun rate of sidewalk repairs. But how legitimate is this objection? Many recent foreclosures were caused in large part by abuses in the real estate industry, including no-documentation loans to people who could not afford the properties they bought. Realtors and mortgage lenders have little basis to argue that the current spike in foreclosures, which the realtors' and mortgage lenders' own malpractices helped create, prevents the city from implementing a reform to fix broken sidewalks, especially if the reform is necessary to avoid an ADA lawsuit.

Another possible objection is that if different contractors repair the sidewalks at different times, inconsistent materials and crafts- 
manship might disrupt the visual unity of the streetscape. To avoid this problem, most cities require contractors to obtain permits that carefully specify the texture, color, cement mix, aggregate material, depth, and surface appearance of the sidewalk repairs. The city also inspects the sidewalk after the work is done to ensure compliance with the permit. If the city makes the repairs, it follows the same specifications. After some weathering, most repairs match the original sidewalk and are barely noticeable.

A more serious problem arises if the required sidewalk repairs amount to a substantial share of an owner's equity. Suppose, for example, a low-income homeowner receives only $\$ 10,000$ after satisfying all of a property's debts at sale and the sidewalk repairs cost $\$ 1,000$. Unless the repairs increase the property value, the cost will reduce the owner's equity by $10 \%$. If paying for sidewalk repairs does create a hardship for low-income owners when they sell their property, cities can offer exemptions or subsidies specifically for these owners.

\section{Pilot Project}

The city can test a point-of-sale program with a pilot project in one or more neighborhoods. To avoid the objection that the project will harm homeowners, the city can undertake the first one in a business district. Repairing cracked sidewalks in a business district with high pedestrian traffic should be a priority for the city. Opponents cannot claim that the pilot project will slow home sales because all the properties will be nonresidential.

A pilot project will not only show the effects of a point-of-sale program but will also enable the city to train inspectors, develop the necessary administrative procedures, and work with realtors and escrow firms to establish the best way to manage the program. By comparing the pilot project area with an otherwise similar control area, an evaluation can be designed to answer many important questions about the point-of-sale program. For instance:

1. How quickly can the city inspect a property after an owner requests an inspection?

2. How many properties require repairs before sale?

3. How much do the required repairs cost?

4. How quickly can the repairs be made?

5. How many city staff are required to inspect properties and make repairs?

6. How large are the repair costs compared to the property sale prices?

7. How quickly does the city recoup the cost of making the repairs?

8. How much must the city charge to recover the cost of inspecting a sidewalk?

9. Does requiring a compliance certificate in the escrow process slow property sales?

10. Do repaired sidewalks increase property values or reduce the time needed to sell a property?

The answers to these and other questions can help to improve the point-of-sale program and demonstrate its effects. If the pilot project is considered a success, the requirement for sidewalk repairs at sale can be adopted in other areas and ultimately citywide.

\section{Four Additional Strategies for Accessible Sidewalks}

My focus is on point-of-sale programs, but four other strategies can help cities comply with the ADA. First, cities can cite prop- erties with severely damaged sidewalks that are a threat to safety and require the owners to pay for repairs as Los Angeles routinely did until 1973. To make this option politically viable, the city can allow owners to defer paying for the repairs until they sell their property. Requiring immediate repairs will increase public safety, reduce barriers to the disabled, and reduce claims from trip-andfall lawsuits. Allowing owners to defer payment until sale means that paying for the repairs will not impose a financial hardship on any owner.

Second, cities can require owners to fix their sidewalks when they apply for a building permit to improve their property. Pasadena, for example, requires sidewalk repairs before issuing any building permit for more than $\$ 20,000$ of improvements. Section 12.04.031 of the Pasadena Municipal Code states, "All such permits, prior to final issuance, shall require a notation that a sidewalk inspection was completed and that either the sidewalk is not in need of repair, that repair has been completed, or that repair has been bonded to the satisfaction of the engineer."

Third, cities can use the revenue from parking meters to pay for sidewalk repairs on the metered streets. Pasadena has used this strategy with great success. When the city agreed to commit the revenues from new parking meters in the Old Pasadena business district to pay for replacing all the sidewalks on the metered streets, merchants and property owners strongly supported the proposal. The city borrowed against the future meter revenues and rebuilt all the sidewalks in Old Pasadena (Kolozsvari and Shoup 2003; Shoup 2005, Chap. 16).

Fourth, cities can enforce the law against parking on sidewalks. Section 22500 of the California Vehicle Code prohibits parking on sidewalks:

"No person shall stop, park, or leave standing any vehicle whether attended or unattended, except when necessary to avoid conflict with other traffic or in compliance with the directions of a peace officer or official traffic control device, in any of the following places:.... (f) On any portion of a sidewalk, or with the body of the vehicle extending over any portion of a sidewalk."

Although parking on the sidewalk is illegal, Fig. 4 shows pic-
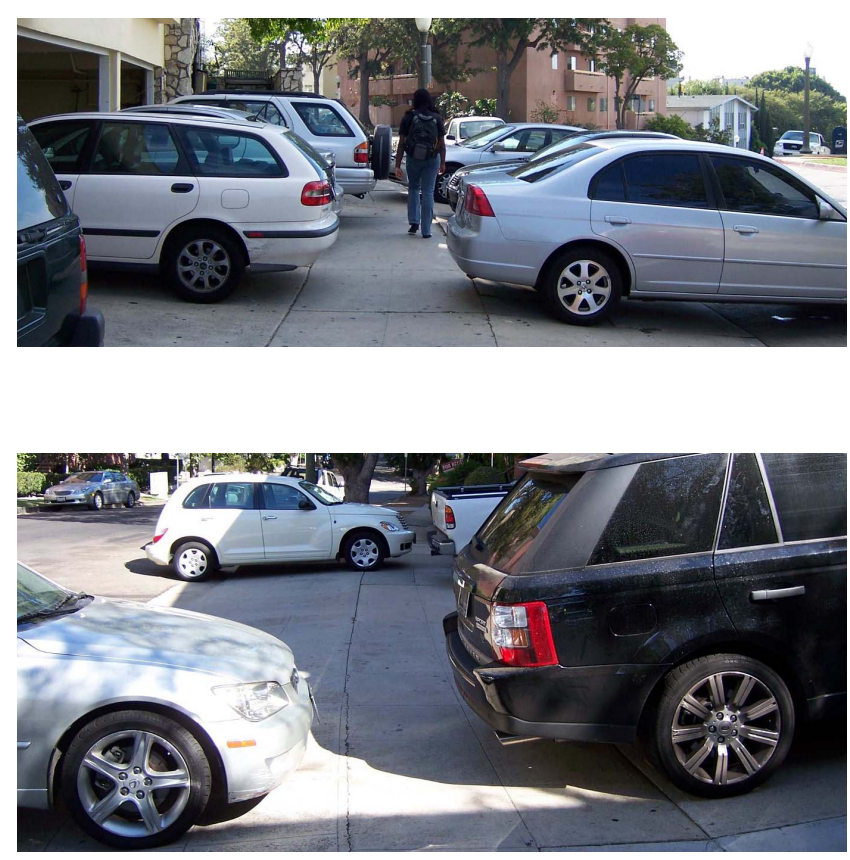

Fig. 4. Cars parked on the sidewalk in Los Angeles 
tures of a common sight in parts of Los Angeles-many cars parked on the sidewalks. Wheelchair users and blind persons find it difficult or impossible to navigate sidewalks blocked by cars. Enforcing the law against parking on sidewalks is a quick way to make cities more accessible to persons with disabilities.

In short, combining a point-of-sale program with these four other programs-(1) citing owners for broken sidewalks and deferring the payments for repairs until sale; (2) requiring repairs when building permits are issued; (3) using parking meter revenue to pay for sidewalk repairs; and (4) citing drivers who park on sidewalks_ can make all the sidewalks accessible.

\section{Putting Cities Back on Their Feet}

Most travel involves sidewalks at the origins and destinations of trips, and some travel is entirely on sidewalks. Nevertheless, sidewalks may seem too mundane for serious academic study. After all, what topic could be more pedestrian than sidewalks?

Perhaps because sidewalks fail gradually rather than collapse spectacularly, many cities have neglected sidewalk maintenance and have thus allowed their neighborhoods to become less walkable. In 2003, however, the Ninth Circuit Court ruled that the ADA applies to public sidewalks. As a result, cities must develop transition plans to ensure that their sidewalks are accessible. In this case, as in many others, what is good for persons with disabilities-repairing broken sidewalks-is good for everyone. The ADA will force cities to do what they should be doing anyway: maintain their public infrastructure.

To ensure a steady flow of sidewalk improvements, cities can require property owners to fix their sidewalks when they sell their property. Before any real estate is sold, the city will inspect the sidewalk fronting the property. If the sidewalk is in good condition, the owner will not be required to do anything. If the sidewalk is broken, however, the owner will be required to fix it before selling the property.

Deferring the obligation to fix sidewalks until sale will help to gain voters' approval, and enforcing the obligation at sale will ensure owners' compliance, both of which are needed for a successful program. Only property owners with broken sidewalks will pay anything; owners will pay only for the cost of repairing their own sidewalks and owners will not have to pay anything until they sell their property. With only a minimal obligation to repair sidewalks at sale, about half the city's broken sidewalks will be repaired in 10 years. All residents will be able to say, in the words of Danish urban designer Jan Gehl, "How nice it is to wake up every morning and know that your city is a little better than it was the day before."

Our sidewalks have decayed slowly, and they can improve slowly. A better world often arrives in small steps, but we need reasons to take these steps. With a point-of-sale program, all property owners will, sooner or later, have to do their part. Walkable cities need good sidewalks, and requiring sidewalk repairs at sale will help put cities back on their feet.

\section{Acknowledgments}

The writer would like to thank Alexander Beata, Amanda Bornstein, Sabrina Bornstein, Stephen Brumbaugh, Matthew Bruno, Stephanie Ericson, Niall Huffman, Joseph Holmes, John Kenyon, David King, Michael Manville, Kathleen Matchett, Daniel Mitchell, Eric Morris, Andrea Osgood, Matthew Palmer, Gregory Pierce, Jeffrey Rabin, Adina Ringler, Anthony Rozzi, Linda Samuels, Patricia Shoup, Michael Smart, Ariel Strauss, Jacob Veverka, Andrew Whittemore, Jonathan Williams, Jonathan Yorde, and two anonymous referees for their valuable editorial contributions. The writer is also grateful to the University of California Transportation Center and the Ziman Center for Real Estate for supporting this research.

\section{References}

Barden v. City of Sacramento. (2002). "Class action settlement agreement." 〈www.dralegal.org/downloads/cases/barden/settlement.pdf $\rangle$ (Aug. 12, 2008).

Kohrman, D., and Nepveu, J. (2008). "Court allows challenge for safe sidewalks." Elder Law Forum, XXI(2), 5-6.

Kolozsvari, D., and Shoup, D. (2003). "Turning small change into big changes." Access No. 23, Fall, 2-7, 〈http://shoup.bol.ucla.edu/ SmallChange.pdf $\rangle$ (Dec. 14, 2008).

Martin, H. (1996). "Panel urges mandate on gas shut-off valves." Los Angeles Times, 〈www.its.ucla.edu/shoup/shut-offvalves.pdf $\rangle$ (Dec. 8, 2008).

Martin, H. (1997). "Gas shut-off valves mandated: Realtors fear action may hurt housing sales." Los Angeles Times, (www.its.ucla.edu/ shoup/safetyvalvesmandated.pdf $\rangle$ (Dec. 8, 2008).

Shoup, D. (1980). "Financing public investment by deferred special assessment." Natl. Tax J., XXXIII(4), 414-429, 〈www.sppsr.ucla.edu// dup/people/faculty/shoup/NationalTaxJournal.pdf (Dec. 8, 2008).

Shoup, D. (1990). "New funds for old neighborhoods: California's deferred special assessments." California Policy Seminar, Berkeley, Calif.

Shoup, D. (1994). "Is underinvestment in public infrastructure an anomaly?" Methodology for land and housing market analysis, Gareth Jones and Peter Ward, eds., UCL Press, London, 236-250, 〈www.sppsr.ucla.edu//dup/people/faculty/shoup/IsUnderinvestment.pdf $\rangle$ (Dec. 8, 2008).

Shoup, D. (1996). "Regulating land use at sale." J. Am. Plan. Assn., 62(3), 354-372, 〈http://shoup.bol.ucla.edu/Regulation_at_Sale.pdf $\rangle$ (Dec. 8, 2008).

Shoup, D. (2005). The high cost of free parking, Planners Press, Chicago. 